\title{
OPTIMIZATION OF HUMAN RESOURCE MANAGEMENT AND RAWLS' THEORY OF JUSTICE
}

\author{
SAIRA REHMAN $^{1}$, AND MUHAMMAD AMIN ${ }^{2}$ \\ ${ }^{1}$ Department of Administartive Sciences, University of The Punjab, Lahore, Pakistan \\ ${ }^{2}$ Department of Electrical Engineering, Institute of Space Technology, Islamabad, Pakistan \\ Email: Dr.Ing.Amin@gmail.com
}

\begin{abstract}
Rawls Theory of Justice (RTJ) sheds light on the importance of fairness, justice and equity in society however application of RTJ in human resource management for better organizational performance and output presents some challenges which are harder than when applied to the society, e.g. fulfillment of "blind position" prerequisite. By applying Rawls theory of justice one can infer essential roles of fairness in human resource management of an organization and the modus operandi used for its implementation to increase its productivity or output. This paper discusses the primary issues seen in application of Rawls theory of justice (RTJ) in human resource management. It discusses essential ingredients of RTJ and prerequisites of applying this theory such as well-ordered society, acceptance of laws and regulation by majority. It further discusses what happens if these prerequisites are not fulfilled such as lack of wide ranging institutional support on basic rules of fairness and justice, lack of basic liberties and lack of fair equality of opportunities. These problems are examined in the light of RTJ and solutions are suggested for optimized human resource management in any Keywords: Human Resource Management; Optimization of Human Resource Management; Rawls' Theory of Justice; Fairness and Human Resource Management.
\end{abstract}

1. Introduction. Human resource management (HRM) to define in the simplest terms is to manage people effectively in order to achieve organizational goals, i.e. to have the optimum level of input from employees in order to achieve the strategic business objectives of an organization. The primary concern of HR is the management of its workforce within the organization in such a way so that optimum level of output is attained. The paper discusses prior work which has been done in the filed of human resource management and the optimum output which can be achieved in an organization using the Rawlsian theory of justice. The literature sheds light on how organizational fairness, HRM and ethical traditions are practiced in earlier years to achieve justice and fairness in an Organization. Ethics can be linked directly to the organizational practices of moral right or wrong doings which in turn links to justice and fairness being practiced in an organization. It also discusses how procedural justice and fairness can increase employee output and productivity and can result in the betterment of an organization.

In their lengthy review of 80 years of HRM science and practice (Ferris et al,1999) identify the issue of justice and HRM as an interesting and potentially important direction for future work in HRM. The focus of the research cited in this review is at the micro-level of procedural fairness of selection, performance evaluation and compensation systems. Broader ethical issues are ignored ,or mentioned in passing, when they 
are arguably central to the discussion.(Greenwood,2002). This is illustrated in the discussion of accountability and HRM where the authors note 'the presence of multiple audiences' accountability perceptions, and the moderating effects of context and personality differences(Ferris et al,1999,pg 402-403) yet fail to introduce theories of ethical development csr or stakeholder management.

To date only a few theorist have attempted to apply ethical theory directly to HRM (Legge,1996). She arrives at the predictable solution that the outcome of any evaluation of a particular form of HRM will depend upon which ethical principles are applied. In contrast (Miller,1996) provides a micro-level analysis of HRM systems, procedures and outcomes based on a framework of procedural justice. He argues that ethical HRM can be achieved by applying principles of fairness and equality. He concludes that ethical or good HRM practices depends on good employment conditions which in turn depends upon good organizational strategy. The doctrine of utilitarianism does not allow a moral agent to differentiate between the claims of intimates or dependents and those of independents (Petit,1991). (Rawls, 1972) is a highly critical of this principle on the ground that it denies any distinction on this basis amongst persons.

In addition there is a striking feature of the principle of utility that it does not matter how the sum of benefits is distributed among individuals. Thus there is no reason in principle why the greater gains of some should not compensate for the lesser losses of others (Greenwood, 2002). According to (Rawls, 1972) this doctrine is irrational because it is in total contradiction with the fact that in individual, liberties are fundamental to a just society. Indeed individuals rights are entrenched in law and unable to be traded off against the greater needs of society. Acceptance of this argument undermines the utilitarian justification of many HRM policies and practices for example in recent years, most industrialised countries have seen compny downsizing. Moreover the business community now considers downsizing normal practices at large (Orlando,1999). The empirical research on the effects on retrenched employees of downsizing shows that these individuals suffers greatly (Orlando,1990). Yet these actions are justified by being not only in the interest of owners, but of society as a whole (more competitive industry, cheaper goods etc). Such an ethical justification, which fails to recognize whatsoever the rights of others as a constraint on action may be seen as fundamentally flawed (Greenwood,2002).

The introduction of ethical theory and stakeholder theory in the discussion of HRM is a fairly rare and nascent occurance. Whilst the aforementioned writers ruthlessly expose HRM practices as objectifying individuals (Townley,1993), as suppressing resistance and confrontration (Sennet,1999), in short as manipulating employees, they take a critical rather than a normative stance about employees productivity by objectifying and quantitatively judging their output. Questions such as of right or wrong or how should organizations behave do not seem to be addressed by HRM researchers (Greenwood,2002).The fact that the way employees are managed may invite ethical scrutiny appears to have been overlooked (Winstanley and Woodall,2002) in many of the prior researches as explained earlier. The ethical and perspective on justice as an important nuance in organizational output seems to gain much importance over time.

2. Good Human Resource Management Practices. Human resource management in a holistic way is concerned with the overall requirements of the people in an organization so that they can work efficiently. Human resource points towards the softer side i.e. people or employees which are treated as valuable assets. With people comes the role of justice and fairness in organizations such as reward systems, performance measures, promotion and learning opportunities. Fairer the procedures results in maximum/optimum level of productivity from employees. Human resource management has achieved greater and greater significance as the societies are becoming technologically advanced and more complex. This is because with technologically advanced societies, human resource management is also becoming complex. The ever growing needs of the society in various areas of social applications such as legal, psychological, economic, political, environmental etc. are also becoming part and parcel of good human resource management (Ahmad, 2015). Research into various aspects of human existence is bringing out new phenomena and necessitating modified behavior from society as consumers and manufacturers. The necessity for this modified behavior asks for new laws, better manufacturing methods, stoppages on use of certain compounds and all these changes are needed to be incorporated at the organizational level as well so that people could better understand the logic and its implications. For example the emerging concept of green technology has given birth to whole new kind of science, where sustainable products are being used in innumerable ways and in a similar way the concept of 
green management has also given various novel ideas in management that calls for sustainable management i.e. it embodies in its implementation the environmental issues, the issues of sustainability (Kramer, 2014), (Ahmad, 2015). In green management or sustainable management the central role to be played is by the human resource management. Implementing sustainable management raises many questions about personal freedom which is a basic concept in RTJ (Jabbour, 2008). Privatisation has become a very powerful driver that is fundamentally changing many of the ways the human resource management was being run before its widespread use. The overstated benefits of privatization has led the owners and investors to adopt certain measures which trespass the basic rights of employees such as downsizing implemented with different masked schemes such as golden handshake schemes. Such measures which completely overlook the rights of employees should be critically analysed and RTJ provides a good objective evaluation criteria for that. Mercilessly guarding the rights of the corporations while ignoring the employees without any critical justification is in complete contradiction to the concept of fairness and justice as expounded in RTJ. The management of employees according to their talents so that these are not misfits is the task of the employer and not the employees (Downs, 2013).

In short good human resource management practice are evolving at faster rate due to advancement in technology (which propose different methods of manufacturing some of which may be beneficial and others are harmful), science (new facts about earth, environment, universe, human biology are unveiled) and social sciences (psychology, human behavior). RTJ provides a good framework to analyse these HRM practices.

3. Basic Tenets of Rawls Theory Of Justice \& its Application in HRM. The basic tenets of RTJ include first of all how judgment should be done. The ideal concept of "blind position" is very difficult to apply even at societal level. In primitive times it was still possible to follow the concept of blind position since the propagation of information was very slow even after the printing machines were invented. However in today's times where print media, electronic media, internet has been made accessible to a wider majority population of the world, information is carried from one end of the world to the other end in a wink of an eye, the idea of blind position cannot be implemented in its true spirit. At organizational level the situation still becomes worse. Depending on how big an organization is, most of the people are very well known to each other. Furthermore the implications of any judgment by an individual are well known by him whether it would give the person giving judgment, advantages or disadvantages. The "blind position" tenet of RTJ is therefore a weak factor in HRM. This weakness needs to be circumvented in HRM. One way that many organizations have adopted is the method of objective evaluation or key performance indicators. However these are also fundamentally crafted by the humans themselves who know the people being evaluated very well.

Prerequisites for application of RTJ require a well ordered society the majority of which accepts the laws, rules and regulations applicable on them. This prerequisite could be fairly fulfilled and would be easier to implement in case of HRM at organizational level since a very small population is involved as compared to a society at nation or country level. Dissemination of information about rules and regulations at organizational level is easy however drafting the rules at smaller level do not follow true spirit of convincing the employees and obtaining even the consent of the majority. Therefore in HRM perspective drafting the rules and regulations for the company should be done after thorough brain storming and convincing the majority if well ordered society prerequisite is to be mapped at organizational level in HRM perspective.

As for institutions are concerned which should support rules of fairness and justice, the department of HRM itself could be the main replacement of such an institution at the organizational level. Since HRM department works under the owner or chief executive of the organization, HRM department as an independent institution supporting rules of fairness and justice is an inadequate concept and therefore can only be taken as a partial replacement in its current form where it is not an independent sort of entity in an organization.

The idea of basic liberties or personal freedom plays a pivotal role in RTJ however by and large the idea of basic liberties is only applicable in HRM perspective at a very rudimentary level. It seems that commercial organizations which are competing in the market, it is very difficult to give kind of basic liberties that they should enjoy as a way of personal freedom. But it is not altogether true. There are many companies which are following revolutionary changes and are giving the people much more basic liberties which organizations of earlier times never envisioned. Some large banks have made their smaller units almost completely independent. Workers in certain corporations decide themselves which projects they will do. There are many 
similar examples. Equality of opportunities is another basic tent of RTJ that is almost in head-on contradiction with the HRM practices at the organizational level. Whereas RTJ demands that people with lesser capabilities or access should be greatly facilitated so that they are not at disadvantage because of their inherent short comings or lesser incapabilities, in HRM practices, the companies expect an average performance level from a person of certain skills regardless of his/her inherent disabilities. In addition to that if the person or persons in question are below the level of their expectation, they might become prey of downsizing. Still worse would be the case where persons have improved their skills tremendously and their level of skills is much higher than the expected. Even in such a case the persons are expelled from the organizations because the forecasting department of the organizations could not accurately predict the sales or any other reason.

4. Conclusion. From the above discussion it can be concluded that HRM practices are evolving rapidly because of many factors which involve faster progress in technology, science and understanding of human behavior. This is making the process of HRM very complex and a framework is essential which can be applied to evaluate HR practices for sustainable management. We have argued that one such basic framework can be the RTJ which has basically been elaborated in the context of a society at a nation or country level. Its applications in the global perspectives have been discussed by many authors but it application in narrower perspective at organizational level for human resource management has been explored in this paper.

It has further been brought out that certain aspects of RTJ when brought at the organizational level and are implemented, these become problematic while other aspect become easier to implement. For example the "blind position" hypothesis becomes extremely difficult to be applied at the organizational level, although the level of difficulty will depend on the size of the organization. In smaller organizations everyone knows every other person so blind position hypothesis loses its meanings all together. In other cases the evaluators normally judge persons which are working under them and in that case also the situation amounts to the same thing. Similarly the equality of opportunities is also in direct conflict with normal HRM practices. Whereas at societal level this means more privileges, more accessibility for people with disabilities, at organizational levels no such HRM practices are carried out. Even if the person has enhanced its abilities, the organization may not give any award because of constraints which are not the result of any of the misgivings of the employee. The prerequisite of well-ordered and well informed society on the other hand is much easier to attain in HRM because of relatively small number of people which work in an organization.

\section{REFERENCES}

[1] Ahmad, S. (2015). Green Human Resource Management: Policies and practices. Cogent Business \& Management, 4(2), 1-13.

[2] Downs, Y. and Swailes, S. (2013). A capability approach to organizational talent management. Human Resource Development International, 16(3), 267-281.

[3] Ferris, G. R., Hochwarter, W. A., Buckley, M. R., Harrell-Cook, G., \& Frink, D. D. (1999). Human resources management: Some new directions. Journal of management, 25(3), 385-415.

[4] Greenwood, M. R. (2002). Ethics and HRM: A review and conceptual analysis.Journal of Business Ethics, 36(3), 261-278.

[5] Jabbour, C.J.C, and Santos, F.C.A (2008). The central role of human resource management in the search for sustainable organizations. The International Journal of Human Resource Management, 19(12), 2133-2154.

[6] Kramar, R. (2014). Beyond strategic human resource management: is sustainable human resource management the next approach?. The International Journal of Human Resource Management, 25(8), 1069-1089.

[7] Legge, K. (1996). Morality bound. People Management, 25(2), 34-36.

[8] Miller, P. (1996). Strategy and the ethical management of human resources. Human Resource Management Journal, 6(1), 5-18.

[9] Orlando, J. (1999). The Fourth Wave. Business Ethics Quarterly, 9(2), 295-314.

[10] Pettit, P. (1991). Consequentialism In P. Singer (Ed.) A Companion to Ethics. 
[11] Rawls, J. (1972). A theory of justice. clarendon press oxford.

[12] Sennet, R. (1999). how work destroys social inclusion. new statesman.

[13] Townley, B. (1993). Foucault, power/knowledge, and its relevance for human resource management. Academy of management review, 18(3), 518-545.

[14] Winstanley, D., \& Woodall, J. (2000). The ethical dimension of human resource management. Human Resource Management Journal, 10(2), 5-20.

[15] Zabalza, K. and Matey, J. (2011). Privatisation and changes in human resource management: evidence from Spain. The International Journal of Human Resource Management, 22(8), $1741-1764$ 